\title{
Tracheostomy in the COVID19 Patients: Our Experience in 12 Cases
}

\author{
Pradeep Pradhan $^{1}(1) \cdot$ Abhijeet Kumar Mishra $^{1} \cdot$ Yash Mittal $^{1} \cdot$ Anindya Nayak $^{1} \cdot$ \\ Chappity Preetam $^{1} \cdot$ Sourav Sarkar $^{1} \cdot$ Dillip Kumar Samal $^{1} \cdot$ Pradipta Kumar Parida $^{1}$
}

Received: 25 November 2020/ Accepted: 5 January 2021/Published online: 12 January 2021

(C) Association of Otolaryngologists of India 2021

\begin{abstract}
The incidence of tracheostomy has been significantly increased with the increase of patients admitted to the intensive care units. Looking into the literature, there have been various protocols proposed in the past for tracheostomy in COVID 19 patients. In the present case series, we have presented our experience of surgical tracheostomy in COVID 19 patients. It is a retrospective case series consisting of 12 COVID 19 patients who underwent tracheostomy from April 2020 to October 2020. We have discussed the tracheostomy in COVID 19 patients with references to their respective indication, location, the procedure, postoperative care and clinical outcomes. Of 12 patients, 6 were operated in the COVID ICU and 6 were operated in the COVID OT. The average duration of the intubation was 4 days (range 3-7 days). The average period of weaning was found to be $65 \mathrm{~h}$ (range $48 \mathrm{~h} 80 \mathrm{~h}$ ). Of 4 patients associated with comorbidities, two had died $48 \mathrm{~h}$ after the surgery. The Primary indication of the tracheostomy can be made flexible based on the infrastructure of the hospital to accommodate increased patient load in a developing country like India. The location and surgical approach does not significantly affect the clinical outcomes of tracheostomy, and it can be safely performed in ICU/OT with adequate ventilation. Irrespective of the COVID status of the patients, Personal Protective Equipment (PPE) can ensure adequate protection to the health care personals preventing the spread of infection.
\end{abstract}

Pradeep Pradhan

padiapradhan@gmail.com

1 Department of ENT and Head Neck Surgery, All India Institute of Medical Sciences (AIIMS), Bhubaneswar, Odisha 751019, India
Keywords Tracheostomy · COVID $19 \cdot$ Outcomes

\section{Introduction}

Tracheostomy is considered as the definitive surgical procedure performed in an emergency setup for airway obstruction and its incidence is always increased with an increase in the hospital stay, especially in the intensive care unit [1]. In the pandemic of COVID 19, it is considered as one of the high-risk surgical procedures amongst all because of the chance of spread of infection among the health care personals. It is mostly indicated in patients with prolonged intubation in severe COVID pneumonia to improve weaning from the ventilator and to prevent the tracheal stenosis [2]. Again, later can be performed in emergency as a life-saving procedure for upper airway obstruction of various aerodigestive pathologies. Being an aerosol generating procedure, tracheostomy is preferably deferred and often advised to perform two weeks after the endotracheal intubation in patients with severe COVID pneumonia [3]. The location of the tracheostomy can be varied, i.e., it can be performed in the ICU or in a wellventilated operation theatre [4], to reduce the virus load. The latter depends upon the infrastructure of the hospital, including the availability of the COVID operation theatre and the health care resource utilization. Tracheostomy can be performed through the percutaneous or open surgical tracheostomy depending upon the surgeon and the location of the surgical procedure. Because of less disruption of the airway, surgical tracheostomy is often preferred to the percutaneous tracheostomy, which is usually performed by an Otorhinolaryngologist [5]. Tracheostomy care, along with postoperative rehabilitation, are the vital steps not only to prevent the blockage of the tube but also to enhance 
for early weaning from the ventilator, especially for the patients admitted in the ICU. In spite of all the diversity in the management protocol of the COVID 19, it is the personal protective equipment (PPE) that can ensure adequate protection against the COVID 19, especially to the health care professionals during the surgical procedure. In the present case series, we have shared our experience of tracheostomy in COVID 19 patients in a tertiary care hospital.

\section{Materials and Methods}

It is a retrospective case series consisting of 12 COVID 19 patients who underwent tracheostomy, from April 2020 to October 2020 in All India Institute of Medical Sciences Bhubaneswar, a tertiary care referral hospital.

\section{Surgical Technique}

After the informed and written consent from the patients and/or relatives, the surgical procedure was performed on each patient. The operative procedure was almost similar to the standard open surgical tracheostomy with few modifications were done to prevent the risk of infection of the virus. Surgical procedures were undertaken in the ICU/operation theatre, specially designed for the COVID 19 patients. All the surgeries were performed by a team of surgeons in the Department of Otolaryngology and Head Neck Surgery followed a fixed protocol of safety measures. Each patient had undergone COVID testing (Antigen/Reverse transcription polymerase chain reaction) depending on the time of presentation to the department. Reverse transcription polymerase chain reaction (RTPCR) was advised especially for the elective surgeries. Antigen testing for COVID 19 was performed in patients who required emergency tracheostomy. When the surgery was to serve in the operation theatre (OT), the patient was shifted from ICU to the OT by a particular transport team through an isolated corridor. All the tracheotomies were performed by the team of doctors well equipped with PPE, including the face shield (Fig. 1). A tracheal stoma was made in each case in the region of second/third tracheal ring. The cuff pressure was maintained at $25-30 \mathrm{~cm} \mathrm{H}_{2} 0$, especially for patients required for positive pressure ventilation.

\section{Results}

Of 12 patients who underwent tracheostomy, 6 were operated in the COVID ICU and the rest 6 were operated in the COVID OT. The average duration of the endotracheal intubation was 4 days (range 3-7 days). Seven patients underwent tracheostomy for the severe COVID 19

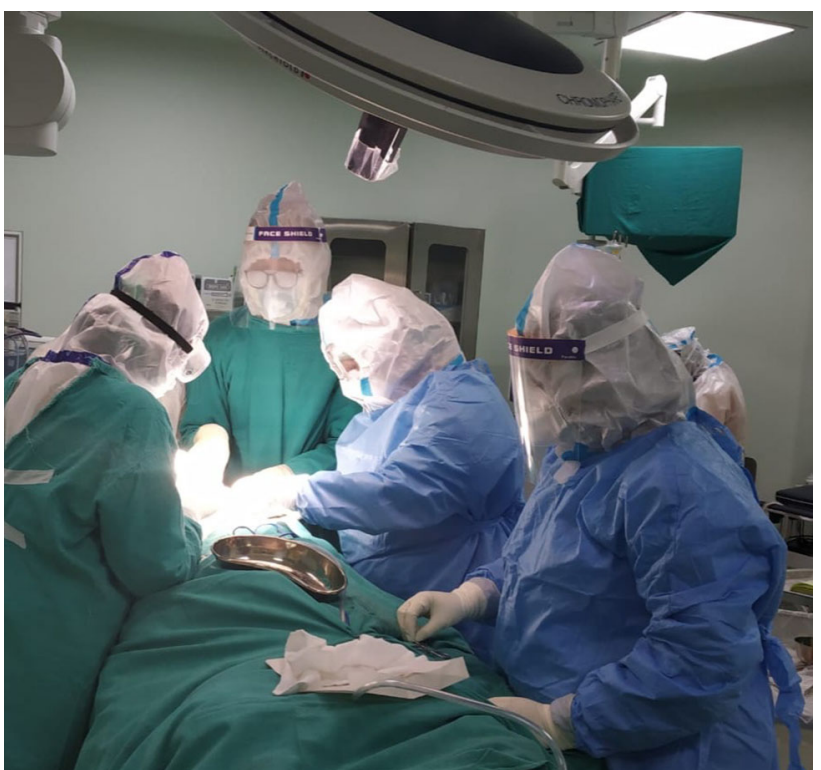

Fig. 1 Demonstrates the COVID OT, where the surgical tracheotomies were performed ensuring all protective measures

infection [COVID-19 Reporting and Data System/CORADS 5, SPO $2<90 \%$ ). Of the rest 5 patients, 2 patients had a history of head trauma who underwent the neurosurgical procedure, later needed long-term ventilatory support. One patient was presented with a suicidal cut throat, one with bilateral abductor palsy and the other with advanced malignancy of the oropharynx who was tracheotomised in the emergency department as live saving procedure. The average duration of the surgery was $31 \mathrm{~min}$ (range 25-38 $\mathrm{min}$ ). The average time of the first change of the tracheostomy tube was ranged from 4 to 8 days (average 6 days). The staff nurse in the intensive care unit and attendant, were adequately trained for the routine care of the tracheostomy tube, especially the regular suctioning of the tracheal secretion to prevent the blockage of the tube. Supportive care like saline nebulization, mucolytics and chest physiotherapy were started on a priority basis, six hours after the surgery. Of the 7 patients with severe pneumonia, two had died in the ICU, $48 \mathrm{~h}$ after the tracheostomy due to extensive involvement of bilateral lungs. The average period of weaning was found to be $65 \mathrm{~h}$ (range $48 \mathrm{~h} 80 \mathrm{~h}$ ). Of the 12 patients, 4 patients were associated with chronic comorbidities, i.e., Diabetic/bronchial asthma/ renal disease. Among them, 3 patients were operated in the COVID ICU and one patient was operated in the COVID OT and two of them died $48 \mathrm{~h}$ after the surgery. The patients were followed up for a minimum period 2 months to maximum 6 months after the surgery. None of the patients had attempted for decannulation until the final follow-up (Table 1). 
Table 1 Demographic data and the clinical profile of the tracheotomised patients

\begin{tabular}{|c|c|c|c|c|c|c|c|c|}
\hline $\begin{array}{l}\text { Serial } \\
\text { no. }\end{array}$ & Age/sex & Indication & $\begin{array}{l}\text { Duration of } \\
\text { intubation } \\
\text { (days) }\end{array}$ & Comorbidites & $\begin{array}{l}\text { Location } \\
\text { of surgery }\end{array}$ & $\begin{array}{l}\text { Duration of } \\
\text { surgery (min) }\end{array}$ & $\begin{array}{l}\text { Tube change } \\
\text { After the } \\
\text { surgery } \\
\text { (days) }\end{array}$ & $\begin{array}{l}\text { Duration of weaning } \\
\text { after surgery }(\mathrm{h})\end{array}$ \\
\hline 1 & $85 / \mathrm{M}$ & $\begin{array}{l}\text { COVID } \\
\text { Pneumonia }\end{array}$ & 7 & $\mathrm{DM}+\mathrm{HTN}+\mathrm{CVA}$ & $\begin{array}{l}\text { COVID } \\
\text { OT }\end{array}$ & 28 & 5 & 48 \\
\hline 2 & $40 / \mathrm{F}$ & $\begin{array}{l}\text { COVID } \\
\text { Pneumonia }\end{array}$ & 3 & DM & $\begin{array}{l}\text { COVID } \\
\text { ICU }\end{array}$ & 30 & 7 & 72 \\
\hline 3 & $42 / \mathrm{M}$ & $\begin{array}{l}\text { RTA with } \\
\text { Subdural } \\
\text { hematoma }\end{array}$ & 5 & DM & $\begin{array}{l}\text { COVID } \\
\text { ICU }\end{array}$ & 35 & 7 & 72 \\
\hline 4 & $70 / \mathrm{F}$ & $\begin{array}{l}\text { COVID } \\
\text { Pneumonia }\end{array}$ & 4 & $\mathrm{DM}+\mathrm{HTN}$ & $\begin{array}{l}\text { COVID } \\
\text { ICU }\end{array}$ & 29 & 6 & \\
\hline 5 & $40 / \mathrm{F}$ & $\begin{array}{l}\text { COVID } \\
\text { Pneumonia }\end{array}$ & 4 & HTN & $\begin{array}{l}\text { COVID } \\
\text { ICU }\end{array}$ & 35 & 4 & 72 \\
\hline 6 & $25 / \mathrm{F}$ & $\begin{array}{l}\text { COVID } \\
\text { Pneumonia }\end{array}$ & 2 & Nill & $\begin{array}{l}\text { COVID } \\
\text { ICU }\end{array}$ & 30 & 5 & 80 \\
\hline 7 & $55 / \mathrm{M}$ & $\begin{array}{l}\text { COVID } \\
\text { Pneumonia }\end{array}$ & 5 & HTN & $\begin{array}{l}\text { COVID } \\
\text { ICU }\end{array}$ & 25 & 7 & \\
\hline 8 & $60 / \mathrm{F}$ & $\begin{array}{l}\text { B/L Abductor } \\
\text { palsy with } \\
\text { stridor }\end{array}$ & Nill & Nill & $\begin{array}{l}\text { COVID } \\
\text { OT }\end{array}$ & 30 & 8 & 50 \\
\hline 9 & $22 / \mathrm{M}$ & $\begin{array}{l}\text { COVID } \\
\text { Pneumonia }\end{array}$ & 5 & Nill & $\begin{array}{l}\text { COVID } \\
\text { OT }\end{array}$ & 38 & 5 & 70 \\
\hline 10 & $47 / \mathrm{M}$ & $\begin{array}{l}\text { Prolonged } \\
\quad \text { intubation }\end{array}$ & 3 & CVA & $\begin{array}{l}\text { COVID } \\
\text { ICU }\end{array}$ & 35 & 6 & 50 \\
\hline 11 & $55 / \mathrm{M}$ & Cut throat injury & Nill & $\mathrm{DM}$ & $\begin{array}{l}\text { COVID } \\
\text { OT }\end{array}$ & 28 & 7 & 70 \\
\hline 12 & $48 / \mathrm{M}$ & $\begin{array}{l}\text { Cancer of } \\
\text { oropharynx }\end{array}$ & Nill & $\mathrm{DM}$ & $\begin{array}{l}\text { COVID } \\
\text { OT }\end{array}$ & 30 & 5 & 72 \\
\hline
\end{tabular}

RTA, road traffic accident; B/L, bilateral; DM, diabetes; HTN, hypertension; CVA, cerebrovascular accident; ICU, intensive care unit

\section{Discussion}

Due to the increased number of COVID positive cases in the pandemic period, the rate of severe COVID pneumonia has been found to be increased in the past, necessitating increased ICU admission and the tracheostomy [2]. Later is considered as a vital surgical procedure for early weaning from the ventilator after the cessation of the insulting factors [6, 7]. Being an aerosol generating procedure, there is a high chance of spread of infection to the health care personals during the surgery [8]. Hence it is always a challenge for an otolaryngologist to perform the surgery, avoiding the risk of infection. Different treatment guidelines have been proposed in the past for better perioperative management of COVID 19 patients. The variation in the management protocol could be due to the availability of the infrastructure, expenses towards the health sector and to accommodate the massive caseload of COVID 19 patients in the ICU, especially in a developing country like India [2]. Being an aerosol generating procedure, tracheostomy is usually deferred and often advised to perform 2 weeks after the endotracheal intubation in patients with severe COVID pneumonia [3]. In contrast, in the present series, the average period of intubation was 4 days (range 3-7 days). The relatively early tracheostomy could be due to the limited capacity of ICU beds to accommodate the patient load and to hasten the period of weaning from the ventilator. When we compare the surgical approaches, no significant difference was noted between the percutaneous and surgical tracheostomy, although the latter is often preferred to the percutaneous tracheostomy because of less disruption of the airway [5]. In contrast, in the present series, all the tracheotomies were performed through surgical methods by a team of surgeons consisted of otolaryngologists. Based on the infrastructure of the hospital, the procedure can be successfully performed in the ICU or in the OT. The most important aspect of the location of surgery is the ventilation, i.e., the surgical procedure is advised to perform in a well-ventilated OT. The modular OT with the HEPA filter can fulfil the above purpose, 
reducing the virus load as demonstrated in our series. As documented in the literature, one air exchange in the operative room can decrease the viral load by $63 \%$ [9]. In the present case series, of the 12 patients, 6 patients were operated in the ICU and 6 patients were operated in the COVID operation theatre. In both settings, adequate attention was given for the PPE irrespective of the COVID status before the surgery as the sensitivity does not reach to $100 \%$ [10]. In the present case series, we did not find any health care personals including the operating surgeons were infected with the disease and there was no difference between these two settings. The tracheostomy of the COVID pneumonia patient was almost the same as that of conventional surgery. Some authors propose to create the tracheal flaps in spite of making a stoma for ease of changing the tube in the postoperative period. In the present case, we have followed the standard procedure and a tracheal stoma was created in each patient in the region of the second/third tracheal ring. The average duration of the surgery was found to be $31 \mathrm{~min}$, and there was no significant difference detected between the two locations, i.e., in the ICU and the OT $(p \geq 0.05)$. Postoperative care was almost similar to standard tracheostomy, although special attention was paid towards the blockage of the tube/ requirement of change of the tracheostomy. Chest physiotherapy and systemic mucolytics were started early in the postoperative period to prevent tube blockage and for the improvement of the pulmonary reserve. The average duration of the tracheostomy tube change was documented to be 5 days, although in one case, it was done after $72 \mathrm{~h}$ of tracheostomy due to the displacement of the tube in a patient with a suicidal cut throat. In the present case series, the average time of weaning off the COVID pneumonia patients was $65 \mathrm{~h}$ (range $48 \mathrm{~h}-80 \mathrm{~h}$ ) and no significant difference was noted between the two locations. Two patients had died in the postoperative period, which could be due to the associated comorbidities and elder age of presentation. Although there is no direct evidence of the severity of the COVID 19 disease with the pre-existing comorbidities [11-13], the mortality in our series has predominantly happened in these patients. None of the Health care personals, including the operating surgeons, were infected during the management of COVID 19 patients.

\section{Conclusion}

The COVID 19 infection has resulted in an increasing number of patients admitted to the ICU with COVID pneumonia, which later increased the incidence of tracheostomy in the recent past. It not only ensures a definitive airway to the organic obstruction but also hastens the weaning from the ventilator, especially in severe COVID 19 pneumonia with long term intubation. The Primary indication of the tracheostomy can be made flexible based on the infrastructure of the hospital to accommodate increased patient load in a developing country like India. The location and surgical approach does not significantly affect the clinical outcomes of tracheostomy and it can be safely performed in ICU/OT with adequate ventilation. Irrespective of the COVID status of the patients, PPE can ensure adequate protection to the health care personals preventing the spread of infection.

Funding No funding received.

\section{Compliance with Ethical Standards}

Conflict of interest All authors have declared that there is no conflict of interest among the author.

Ethical Approval All procedures performed in studies involving human participants were in accordance with the ethical standards of the institutional and/or national research committee and with the 1964 Helsinki declaration and its later amendments or comparable ethical standards.

Informed Consent Informed consent was obtained from all individual participants included in the study.

\section{References}

1. Wu Z, McGoogan JM (2020) Characteristics of and important lessons from the coronavirus disease 2019 (COVID-19) outbreak in China: summary of a report of 72314 cases from the Chinese center for disease control and prevention. JAMA 323(13):1239-1242. https://doi.org/10.1001/jama.2020.2648

2. John Hopkins University (2020) Coronavirus Resource Centre. https://coronavirus.jhu.edu/map.html. Accessed 10 Apr 2020.

3. American Academy of Otolaryngology and Head and Neck Surgery (2020) AAO position statement: tracheotomy recommendations during the COVID-19 pandemic. https://www. entnet.org/content/aao-position-statement-tracheotomy-recommen dations-during-covid-19-pandemic. Accessed 2 Apr 2020

4. Chow TT, Kwan A, Lin Z, Bai W (2006) Conversion of operating theatre from positive to negative pressure environment. J Hosp Infect 64(4):371-378. https://doi.org/10.1016/j.jhin.2006.07.020

5. Tay JK, Khoo ML, Loh WS (2020) Surgical considerations for tracheostomy during the COVID-19 pandemic: lessons learned from the severe acute respiratory syndrome outbreak. JAMA Otolaryngol Head Neck Surg. https://doi.org/10.1001/ jamaoto.2020.0764

6. Dawson D (2014) Essential principles: tracheostomy care in the adult patient. Nurs Crit Care 19(2):63-72. https://doi.org/ 10.1111/nicc.12076 (PMID: 24529106)

7. Kutsukutsa J, Kuupiel D, Monori-Kiss A, Del Rey-Puech P, Mashamba-Thompson TP (2019) Tracheostomy decannulation methods and procedures for assessing readiness for decannulation in adults: a systematic scoping review. Int J Evid Based Healthc 17(2):74-91. https://doi.org/10.1097/XEB.0000000000000166 (PMID: 31162271) 
8. Tran K, Cimon K, Severn M, Pessoa-Silva CL, Conly J (2012) Aerosol generating procedures and risk of transmission of acute respiratory infections to healthcare workers: a systematic review. PLoS ONE 7(4):e35797. https://doi.org/10.1371/journal.pone. 0035797

9. Coia JE, Ritchie L, Adisesh A, Makison Booth C, Bradley C, Bunyan D, Carson G, Fry C, Hoffman P, Jenkins D, Phin N, Taylor B, Nguyen-Van-Tam JS, Zuckerman M (2013) Healthcare infection society working group on respiratory and facial protection. Guidance on the use of respiratory and facial protection equipment. J Hosp Infect 85(3):170-182. https://doi.org/10.1016/ j.jhin.2013.06.020

10. COVID-19: Infection prevention and control (IPC) www.gov. uk/government/publications/wuhan-novel-coronavirus-infection prevention-and-control. Accessed 7 May 2020
11. Hahid Z, Kalayanamitra R, McClafferty B, Kepko D, Ramgobin D, Patel R, Aggarwal CS, Vunnam R, Sahu N, Bhatt D, Jones K, Golamari R, Jain R (2020) COVID-19 and older adults: what we know. J Am Geriatr Soc 68(5):926-929. https://doi.org/10.1111/ jgs. 16472

12. Liu S, Zhi Y, Ying S (2020) COVID-19 and asthma: reflection during the pandemic. Clin Rev Allergy Immunol 59(1):78-88. https://doi.org/10.1007/s12016-020-08797-3 (PMID: 32468411)

13. Tadic M, Cuspidi C, Sala C (2020) COVID-19 and diabetes: is there enough evidence? J Clin Hypertens (Greenwich) 22(6):943-948. https://doi.org/10.1111/jch.13912

Publisher's Note Springer Nature remains neutral with regard to jurisdictional claims in published maps and institutional affiliations. 